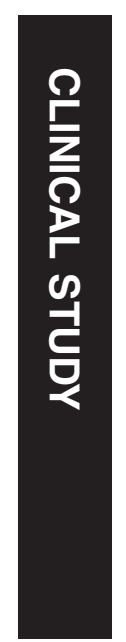

${ }^{1}$ Division of

Ophthalmology and Visual Science, Graduated School of Medical and Dental Sciences, Niigata University, Niigata, Japan

${ }^{2}$ Department of Orthoptics and Visual Sciences, Faculty of Medical Technology, Niigata University of Health and Welfare, Niigata, Japan

Correspondence:

T Fukuchi, Division of Ophthalmology and Visual Science, Graduated School of Medical and Dental Sciences, Niigata University, 1-757 Asahimachi-dori, Niigata 951-8510, Japan Tel: +81 252272296; Fax: +81 252270785 . E-mail: tfuku@med.niigatau.ac.jp

Received: 1 March 2016 Accepted in revised form: 8 July 2016

Published online:

12 August 2016

These data were presented at the 25th annual meeting of Japan Glaucoma Society, 19-21 September 2014, Osaka International Convention Center Grand Cube Osaka, Osaka, Japan.

\title{
Clinical evaluation of microcystic macular edema in patients with glaucoma
}

\begin{abstract}
Purpose To investigate the prevalence of microcystic macular edema (MME) in patients with glaucoma and the relationship between glaucomatous visual field defects and MME. Patients and methods We analyzed 636 eyes of 341 glaucoma patients who underwent spectral domain optical coherence tomography (SD-OCT). MME was defined as vacuoles observed in the inner nuclear layer (INL) on SD-OCT. Quantitative assessment of MME area was performed using en-face imaging obtained swept-source OCT (SS-OCT) and Adobe Photoshop CS6 Extended software. These values were compared with the visual field results with the Humphrey field analyzer.

Results MME was observed in $1.6 \%$ of eyes. The visual field mean deviation (MD), pattern standard deviation (PSD) and visual acuity was significantly worse $(P=0.023, P=0.037$, and $P=0.018$, respectively) in eyes with MME. The average MME area was $2.38 \pm 1.43 \%$. There was no significant correlation between visual field deficits and MME area.

Conclusions The MME detection rate based on general inspection was $1.6 \%$. MME in glaucomatous eyes were associated with worse MD, PSD, and visual acuity. Further research is needed to increase the number of cases to allow for more detailed analysis. Eye (2016) 30, 1502-1508; doi:10.1038/eye.2016.190; published online 12 August 2016
\end{abstract}

\section{Introduction}

Glaucoma is one of the leading causes of acquired blindness worldwide. ${ }^{1,2}$ The typical clinical findings in the ocular fundus of patients with glaucoma include thinning of the neuroretinal rim, optic cup enlargement, and retinal nerve fiber layer defects (NFLDs). ${ }^{3,4}$ Recently, a few studies have reported microcystic macular edema (MME) in patients
N Murata ${ }^{1,2}$, T Togano ${ }^{1}$, D Miyamoto ${ }^{1}$, S Ochiai ${ }^{1}$ and T Fukuchi ${ }^{1}$

with glaucoma. ${ }^{5-7}$ Small vacuoles located in the inner nuclear layer (INL) preponderantly are considered MME. Previous studies have primarily focused on MME in neuromyelitis optica (NMO) $^{8}$ and multiple sclerosis (MS). ${ }^{9,10}$ Breakdown of the blood-retinal barrier or focal inflammation are possible causes of MME. ${ }^{10}$ Wolff $e t a l^{5}$ have reported microcystic changes in the INL of patients with progressive optic nerve atrophy, included glaucomatous optic nerve atrophy. In 36 eyes examined, microcystic changes were observed in 24 eyes with optic neuropathy, of which 12 eyes had glaucoma. That study also demonstrated that microcysts were observed in hyporeflective areas with infrared imaging and red-free imaging obtained using spectral domain optical coherence tomography (SD-OCT). Green et $a l^{11}$ reported the presence of prominent atrophy of the INL in $40 \%$ of eyes with MS eyes and none of the control eyes. Consequently, Wolff et $a l^{5}$ have also hypothesized that one cause of MME is retrograde cellular degeneration, similar to the phenomenon observed in demyelinating inflammatory conditions of the central nervous system and optic nerve. Hasegawa $e a^{7}$ found MME in $6.0 \%$ of eyes with primary open-angle glaucoma (POAG) in a study limited to glaucoma patients. This group has suggested that the presence of MME is associated with NFLDs, ganglion cell layer thinning, and progressive visual field defects. Nevertheless, the prevalence of MME in patients with glaucoma and the relationship between the presence of MME and the pathophysiology of glaucoma remains unclear. In addition, the enface imaging was previously reported as a useful tool to diagnose MME. ${ }^{6}$ However, there has been no study that tried to quantify perimacular lesion area on the en-face imaging. The aim of this study was to investigate the prevalence of MME in patients with glaucoma 
and its association with glaucomatous visual field defects.

\section{Materials and methods}

The present study was approved by the ethics committee of the Niigata University Graduate School of Medical and Dental Science and followed the tenets of the Declaration of Helsinki. We analyzed the records of 636 eyes in 341 consecutive patients with a diagnosis of glaucoma referred to Niigata University Medical and Dental Hospital between October 2010 and January 2015. We included 10 eyes in 7 patients with MME identified using the following method. All glaucoma patients in the database had underwent a routine comprehensive ophthalmic examination, including best-corrected visual acuity (BCVA) using a 5-m Landolt chart, refraction, keratometry, slit-lamp examination, Goldmann applanation tonometry, gonioscopy, indirect ophthalmoscopy, dilated slit-lamp optic disc examination, visual field testing using the 24-2 Swedish Interactive Threshold Algorithm (SITA) Standard Strategy (Humphrey Field Analyzer: HFA; Carl Zeiss Meditec, Inc., Dublin, CA, USA), and 10-2 SITA Standard Strategy, and spectral domain OCT examination with the 3D-OCT 2000 (Topcon, Inc., Tokyo, Japan). Clinical diagnosis of the type of glaucoma was based on European Glaucoma Society $^{12}$ and Japan Glaucoma Society ${ }^{13}$ guidelines. Patients with any associated macular degeneration (eg, age-related macular degeneration, diabetic retinopathy, retinoschisis, retinal vein occlusion, viral retinitis, or epithelial macular membrane) or neurological complications (eg, NMO, MS) were excluded. Patients who underwent posterior segment surgery were also excluded from the analysis.

Well-trained examiners performed 3D-OCT examinations of each eye after dilating the pupil with $0.5 \%$ tropicamide and $2.5 \%$ phenylephrine. The $3 \mathrm{D}-\mathrm{OCT}$ device has a $6-\mu \mathrm{m}$ depth of resolution in tissue, a $20-\mu \mathrm{m}$ transverse resolution, and acquires 50000 axial scans per second. We performed measurements using a $3 \mathrm{D}$ scan protocol with 128 vertical B-scans, comprising 512A-scans per B-scan and 65,536 samplings within a $7 \times 7 \mathrm{~mm}$ cube centered at the fovea. We analyzed highquality images, as indicated by a signal strength score (Qfactor) higher than 65. All 128 B-scans were manually screened to identify the presence of MME in the INL. We applied the same criterion as Gelfand et al ${ }^{10}$ for identifying MME. We assumed that the number of patients who underwent 3D-OCT during the observation period to investigate the prevalence of MME in glaucoma patients.

Ophthalmic and demographic data were compared, both glaucoma patients with MME and patients without
MME, including age at SD-OCT, sex, BCVA, 24-2 mean deviation (MD), and pattern standard deviation (PSD), type of glaucoma and classification of glaucomatous visual field defects. We also detected refractive error (spherical equivalent), 10-2 MD and PSD, the past surgery history, intraocular pressure (pre-operative and postoperative IOP: means of examination another 3 days), glaucoma medications, other medications, and other ophthalmic or systemic disease in only glaucoma patients with MME. Visual field results that were reliable (fixation loss $<20 \%$, false-positive rate $<15 \%$, and false-negative rate $<33 \%$ ) were included in the analysis. The definition and classification of glaucomatous visual field defects were based on the Anderson and Patella criteria. ${ }^{14}$ In addition, we performed swept-source (SS) OCT (DRI OCT-1 Atlantis; Topcon, Tokyo, Japan) in patients with MME to evaluate MME area. SS-OCT has an $8-\mu \mathrm{m}$ depth of resolution in tissue, a $20-\mu \mathrm{m}$ transverse resolution, and acquires 100,000 axial scans per second. Imaging of the macula was performed with $512 \times 256$ axial scans per image within a $6 \times 6 \mathrm{~mm}$ cube centered at the fovea. En-face images of the INL were obtained by En-View, a program in DRI OCT-1 Atlantis, which yields images after automatic flattening at the INL level, using the $6 \times 6 \mathrm{~mm}$ 3D scan. The images were averaging the depth of 11 pixels $(28.6 \mu \mathrm{m})$. Quantitative assessment of MME area in en-face images was performed using Adobe Photoshop CS6 software (Adobe Systems Inc., San Jose, CA, USA). MME was observed as a dark area on en-face images. Primarily, we delineated Existing areas of MME using the lasso tool. Next, the darkest pixel was selected visually using the magnifying tool and color range tool. The fuzziness value of the color range tool was applied 40. Once the selection of the dark MME area was completed satisfactorily, measurement of the selected area in pixels was performed using the Image/Histogram function (See Figure 1 for further details). Three examiners made measurements in a blinded fashion, and the mean value was used to minimize bias. MME area was calculated using the formula: area of MME (pixels)/area of the entire image (pixels) $\times 100(\%)$. MME area was compared with the visual field results with HFA 24-2, 10-2 MD, and PSD.

Statistical analysis was performed using SPSS version 21.0 (IBM Corp., Armonk, NY, USA). Mann-Whitney's $U$-test or $\chi^{2}$-test was used to compare age, gender visual acuity, 24-2 MD value, PSD value, the incidence of advanced stage glaucoma, and Type of glaucoma between eyes with and without MME. Spearman's rank correlation coefficient was used to assess the correlation between MME area and 24-2 MD, 24-2 PSD, 10-2 MD, and 10-2 PSD. Statistical significance was defined as $P<0.05$. 

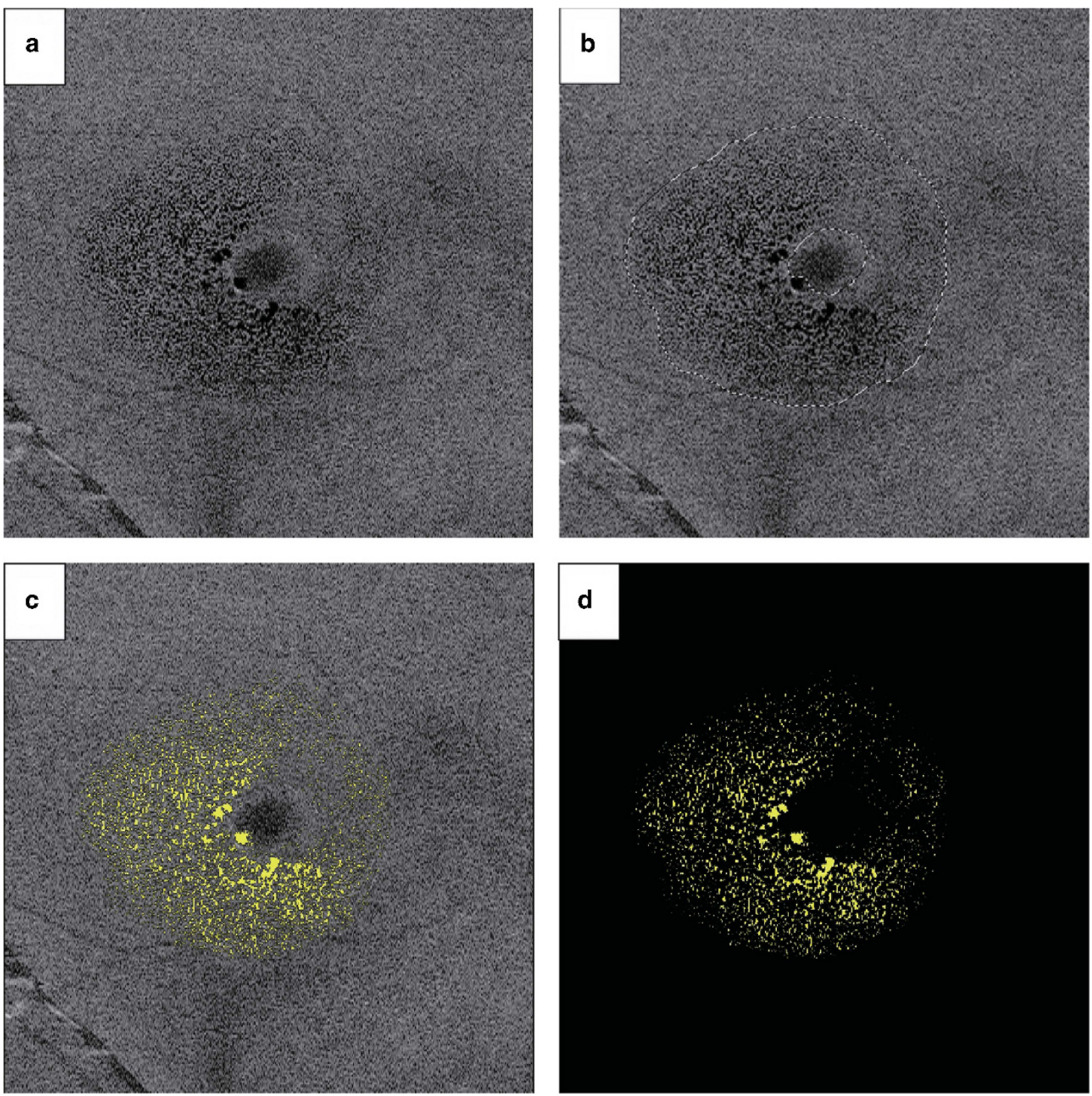

Figure 1 Quantitative analysis of MME area. (a) En-face imaging generated at the INL level. (b) Existing areas of MME were delineated using the lasso tool. (c) The color range tool was used to select all areas with MME (as indicated by dark spots) (d) By changing the color of the selected dark areas to a light color (yellow) and placing these areas against a black background, MME areas were accentuated and more easily appreciated for quantification.

\section{Results}

MME was identified in 10 eyes of 7 patients with glaucoma (1.6\%, 10 of 636 eyes; $2.1 \%, 7$ of 341 patients). Figure 2 shows a representative case. The mean age was $54.9 \pm 9.6$ years. The demographics and clinical characteristics of glaucoma patients with and without MME are shown in Table 1. There were no significant differences in age or sex between patients with MME and patients without MME. However, BCVA, MD value, and PSD value were significantly worse $(P=0.018, P=0.023$, and $P=0.037$, respectively) in eyes with MME. All patients with MME had a diagnosis of open-angle glaucoma, included 6 eyes with POAG and 4 eyes with normal tension glaucoma (NTG). Three patients had MME in both eyes. Mean refractive error was $-4.5 \pm 3.1$ diopters, and mean BCVA was $+0.1 \pm 0.3$ logarithm of the minimum angle of resolution (logMAR). Mean 24-2 MD was $-17.71 \pm 5.05 \mathrm{~dB}$, mean PSD was $12.57 \pm 2.34 \mathrm{~dB}$, mean 10-2 MD was $-21.55 \pm 5.5 \mathrm{~dB}$, and mean PSD was $12.57 \pm 2.34 \mathrm{~dB}$. Two of 10 eyes had moderate glaucomatous visual field defects, while 8 eyes had advanced defects. Eight eyes underwent glaucoma surgery, including trabeculotomy and trabeculectomy (1 eye), single trabeculectomy (5 eyes), and repeat 

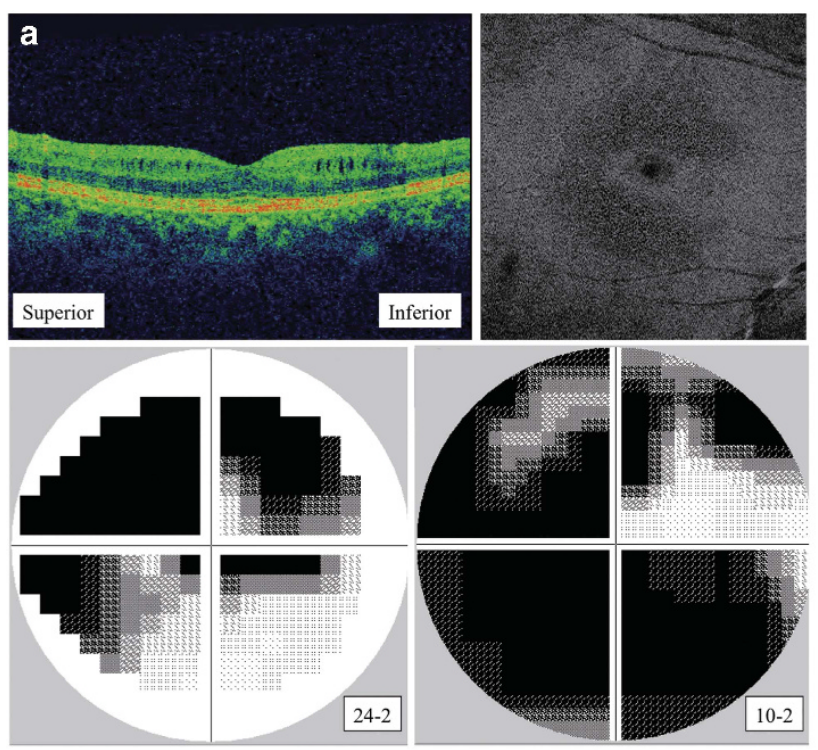
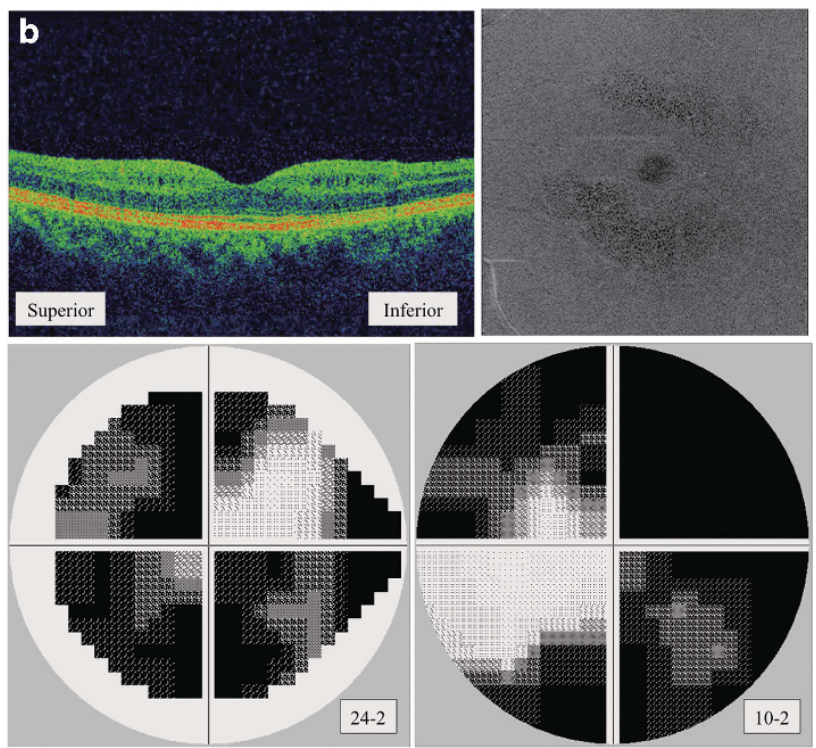

Figure 2 MME observed in SD-OCT B-scan vertical scan image and en-face imaging. (a) A 57-year-old woman with primary openangle glaucoma and MME in her right eye (patient 2). (b) A 64-year-old woman with normal tension glaucoma and MME in her left eye (patient 3). MME was commonly observed under the papillomacular nerve fiber bundle. All patients had visual field defects in the central 24 or 10 degrees.

Table 1 Comparison of characteristics between glaucoma patients With MME and Without MME

\begin{tabular}{|c|c|c|c|}
\hline Variables & Without MME (626 eyes) & With MME (10 eyes) & P-value \\
\hline Age (years) & $61.5 \pm 14.9(11$ to 88$)$ & $54.9 \pm 9.6(36$ to 64$)$ & $0.135^{\mathrm{a}}$ \\
\hline Sex (female/male) & $151 / 183$ & $5 / 2$ & $0.168^{\mathrm{b}}$ \\
\hline BCVA & $20 / 22 \pm 20 / 40(20 / 10000$ to $20 / 16)$ & $20 / 33 \pm 20 / 50(20 / 100$ to $20 / 16)$ & $0.018^{\mathrm{a}}$ \\
\hline 24-2 MD (dB) & $-12.15 \pm 8.23(1.15$ to -30.84$)$ & $-17.71 \pm 5.05(-11.39$ to -26.81$)$ & $0.023^{\mathrm{a}}$ \\
\hline 24-2 PSD (dB) & $9.97 \pm 4.60(0.90$ to 17.46$)$ & $13.19 \pm 2.34(8.62$ to 17.46$)$ & $0.037^{\mathrm{a}}$ \\
\hline \multicolumn{4}{|l|}{ Stage } \\
\hline Advanced, n (\%) & $297(47.4 \%)$ & $8(80.0 \%)$ & \multirow[t]{3}{*}{$0.077^{\mathrm{b}}$} \\
\hline Moderate, n (\%) & $148(23.6 \%)$ & $2(20.0 \%)$ & \\
\hline Early, n (\%) & $181(28.9 \%)$ & $0(0.0 \%)$ & \\
\hline \multicolumn{4}{|l|}{ Type of Glaucoma } \\
\hline POAG & $274(43.8 \%)$ & $6(60.0 \%)$ & \multirow[t]{6}{*}{$0.863^{\mathrm{b}}$} \\
\hline NTG & $272(43.5 \%)$ & $4(40.0 \%)$ & \\
\hline DG & $35(5.6 \%)$ & $0(0.0 \%)$ & \\
\hline PACG & $19(3.0 \%)$ & $0(0.0 \%)$ & \\
\hline XFG & $16(2.6 \%)$ & $0(0.0 \%)$ & \\
\hline SOAG (trauma, steroid) & $10(1.6 \%)$ & $0(0.0 \%)$ & \\
\hline
\end{tabular}

Abbreviations: BCVA, best-collected visual acuity; DG, developmental glaucoma; MME, microcystic macular edema; NTG, normal tension glaucoma; PACG, primary angle closure glaucoma; POAG, primary open-angle glaucoma; XFG, exfoliation glaucoma.

'Hand Motion', 'Counting Finger' were calculated after conversion to 20/10000, 20/5000, respectively. ${ }^{a}$ Mann-Whitney's $U$-test. ${ }^{b} \chi^{2}$-test. Statistically significant associations are marked in bold.

trabeculectomy (2 eyes). Tables 2 and 3 show the demographic data for the 7 patients with MME. Mean MME area was $2.38 \pm 1.43 \%$. Two eyes were excluded from the analysis because of fixation loss or defocused imaging. There was no significant correlation between MME area and any global index of HFA: 24-2 MD $\left(r_{\mathrm{S}}=0.262, P=0.531\right), \operatorname{PSD}\left(r_{\mathrm{s}}=0.143, P=0.736\right)$,
10-2 MD $\left(r_{\mathrm{s}}=-0.571, P=0.139\right)$, and PSD $\left(r_{\mathrm{s}}=-0.310\right.$, $P=0.456)$.

\section{Discussion}

Here we investigated the prevalence of MME based on SD-OCT that was performed routinely in patients 
Table 2 Demographic data of the 7 patients (10 eyes) with microcystic macular edema

\begin{tabular}{|c|c|c|c|c|c|c|c|c|c|c|c|}
\hline Patient & Eye & Sex & $\begin{array}{l}\text { Age } \\
\text { (years) }\end{array}$ & $\begin{array}{l}\text { Refractive } \\
\text { Error (D) }\end{array}$ & $B C V A$ & $\begin{array}{l}\text { Type of } \\
\text { Glaucoma }\end{array}$ & 24-2 MD (dB) & $\begin{array}{c}24-2 P S D \\
(d B)\end{array}$ & $10-2 M D(d B)$ & $\begin{array}{c}10-2 \text { PSD } \\
(d B)\end{array}$ & $\begin{array}{c}\text { MME area } \\
(\%)\end{array}$ \\
\hline 1 & $\mathrm{R}$ & F & 57 & -8.1 & $20 / 66$ & NTG & -11.97 & 17.46 & -21.18 & 15.40 & 3.66 \\
\hline 1 & $\mathrm{~L}$ & $\mathrm{~F}$ & 57 & -7.3 & $20 / 20$ & NTG & -11.39 & 15.16 & -15.75 & 13.45 & 2.37 \\
\hline 2 & $\mathrm{R}$ & $\mathrm{F}$ & 57 & -4.6 & $20 / 22$ & POAG & -20.39 & 13.46 & -28.05 & 12.20 & 3.74 \\
\hline 3 & $\mathrm{R}$ & $\mathrm{F}$ & 64 & \pm 0.0 & $20 / 16$ & NTG & -16.36 & 13.51 & -15.18 & 14.25 & 0.56 \\
\hline 3 & L & $\mathrm{F}$ & 64 & +0.5 & $20 / 20$ & NTG & -23.22 & 8.62 & -22.24 & 12.24 & 1.00 \\
\hline 4 & L & M & 63 & -6.8 & $20 / 20$ & POAG & -12.22 & 13.17 & -22.36 & 13.02 & - \\
\hline 5 & $\mathrm{R}$ & $\mathrm{F}$ & 54 & -6.3 & $20 / 100$ & POAG & -17.14 & 12.81 & -26.19 & 8.89 & 4.37 \\
\hline 5 & $\mathrm{~L}$ & $\mathrm{~F}$ & 54 & -4.5 & $20 / 200$ & POAG & -26.81 & 10.99 & -30.22 & 8.22 & 2.27 \\
\hline 6 & $\mathrm{R}$ & $\mathrm{F}$ & 40 & -6.3 & $20 / 16$ & POAG & -17.87 & 12.72 & -20.28 & 13.55 & - \\
\hline 7 & $\mathrm{R}$ & M & 36 & -1.8 & $20 / 16$ & POAG & -19.69 & 14.03 & -14.02 & 14.47 & 1.13 \\
\hline Mean \pm s.d. & & & $54.9 \pm 9.6$ & $-4.5 \pm 3.1$ & $20 / 33 \pm 20 / 50$ & & $-17.71 \pm 5.05$ & $13.19 \pm 2.34$ & $-21.55 \pm 5.51$ & $12.57 \pm 2.34$ & $2.38 \pm 1.43$ \\
\hline Median & & & 57 & -5.4 & $20 / 20$ & & -17.50 & 13.32 & -21.71 & 13.24 & 2.32 \\
\hline
\end{tabular}

Abbreviations: BCVA, best-corrected visual acuity; F, female; L, left; LogMAR, logarithm of the minimum angle of resolution; M, male; MD, mean deviation; NTG, normal tension glaucoma; POAG, primary open-angle glaucoma; PSD, pattern standard deviation; R, right.

BCVA was analyzed after conversion to $\log$ MAR visual acuity.

Table 3 Surgery, IOP, Medications, and Comorbidities of Patients with microcystic macular edema

\begin{tabular}{|c|c|c|c|c|c|c|c|c|c|}
\hline Patient & Eye & $\begin{array}{c}\text { First } \\
\text { Surgery }\end{array}$ & $\begin{array}{l}\text { Additional } \\
\text { Surgery }\end{array}$ & $\begin{array}{l}\text { IOP } \\
\text { before } \\
\text { surgery } \\
(\mathrm{mmHg})\end{array}$ & $\begin{array}{l}\text { IOP after } \\
\text { last } \\
\text { surgery } \\
(\mathrm{mmHg})\end{array}$ & $\begin{array}{l}\text { Medications for } \\
\text { Glaucoma (past) }\end{array}$ & $\begin{array}{l}\text { Medications for } \\
\text { Glaucoma (after } \\
\text { surgery or } \\
\text { current) }\end{array}$ & Other Medications & $\begin{array}{c}\text { Other } \\
\text { Ophthalmic } \\
\text { Diseases or } \\
\text { Systemic } \\
\text { Disorders }\end{array}$ \\
\hline 1 & $\mathrm{R}$ & TLE & TLE & 15.0 & 11.7 & $\begin{array}{l}\text { Latanoprost, timolol, } \\
\text { brinzolamide, } \\
\text { pilocarpine }\end{array}$ & $\begin{array}{l}\text { Tafluprost, } \\
\text { timolol }\end{array}$ & Methylcobalamin & - \\
\hline 1 & $\mathrm{~L}$ & TLO & TLE & 15.0 & 11.2 & $\begin{array}{l}\text { Latanoprost, timolol, } \\
\text { brinzolamide, } \\
\text { pilocarpine }\end{array}$ & - & & \\
\hline 2 & $\mathrm{R}$ & TLE & - & 16.3 & 9.7 & Latanoprost, timolol & - & - & - \\
\hline 3 & $\mathrm{R}$ & TLE & - & 14.0 & 12.0 & Carteolol, bunazosin & - & Methylcobalamin & - \\
\hline 3 & $\mathrm{~L}$ & TLE & - & 14.0 & 8.3 & Carteolol, bunazosin & - & & \\
\hline 4 & $\mathrm{~L}$ & - & - & 14.0 & - & $\begin{array}{l}\text { Latanoprost, timolol, } \\
\text { dorzolamide }\end{array}$ & $\begin{array}{l}\text { Bimatoprost, } \\
\text { timolol, } \\
\text { brinzolamide }\end{array}$ & - & IV palsy \\
\hline 5 & $\mathrm{R}$ & TLE & TLE & 13.7 & 6.7 & $\begin{array}{l}\text { Latanoprost, } \\
\text { isopropylunoprostone, } \\
\text { timolol, betaxolol, } \\
\text { bunazosin }\end{array}$ & - & - & - \\
\hline 5 & $\mathrm{~L}$ & - & - & 11.7 & - & $\begin{array}{l}\text { Latanoprost, } \\
\text { isopropylunoprostone, } \\
\text { timolol, betaxolol, } \\
\text { bunazosin }\end{array}$ & $\begin{array}{l}\text { Dorzolamide, } \\
\text { travoprost }\end{array}$ & & \\
\hline 6 & $\mathrm{R}$ & TLE & 一 & 13.3 & 8.3 & $\begin{array}{l}\text { Latanoprost, timolol, } \\
\text { brinzolamide, } \\
\text { nipradilol }\end{array}$ & - & 一 & 一 \\
\hline 7 & $\mathrm{R}$ & TLE & - & 14.3 & 8.8 & $\begin{array}{l}\text { Bimatoprost, timolol, } \\
\text { brinzolamide, } \\
\text { dorzolamide }\end{array}$ & - & - & - \\
\hline
\end{tabular}

Abbreviations: IOP, intraocular pressure; IV palsy, trochlear nerve palsy; TLE, trabeculectomy with Mitomycin C; TLO, trabeculotomy.

with glaucoma. The present study demonstrated that MME was observed in $1.6 \%$ of eyes with glaucoma, included six eyes with POAG and four with NTG. To observe the detailed characteristics of MME and the area it involves, patients with MME also underwent SS-OCT with en-face imaging.

Abegg et $a l^{15}$ has reported that $8.8 \%$ of eyes with optic neuropathy showed MME; however, their study included 
patients with optic neuropathy with ischemic, compressive, hereditary, inflammatory, toxic, but not glaucomatous optic neuropathy. Burggraaff et $a l^{16}$ has reported that MME was present in $10.2 \%$ of randomized patients that was not limited to neurological disease investigated over 3 years. Compared with these previous studies that did not include glaucoma patients, the prevalence of MME is lower in glaucomatous eyes. Furthermore, previous research on patients with glaucoma ${ }^{7}$ had found MME in $6.0 \%$ of eyes, which is higher than the prevalence observed in the present study. That previous study did not include any patients with MME in both eyes, compared with 3 of 7 patients in the present study. In the present study, we performed measurements using a 3D scan protocol used in daily clinical examinations to detect the presence of MME. It raises the possibility that the detection rate is changed by using other protocols or OCT models. In addition, we infer that these discrepancies are due to differences in the patient background in comparison with the previous research on glaucoma. ${ }^{7}$ However, their details are unknown.

Wolff et $a l^{6}$ have reported that major cause of optic atrophy with MME was hereditary optic atrophy (75\%). Although the round microcysts network was found in 15 cases (17.6\%) of optic atrophy caused by POAG. The present study investigated all consecutive patients with glaucoma over 4 years, not limited to patients with advanced glaucomatous visual field defects. If we limited study patients to those with advanced glaucoma, there is a possibility that the observed prevalence of MME would increase. In the present study, moderate glaucomatous visual field defects classified based on 24-2 results were observed in 2 eyes (20.0\%), compared with 8 eyes (80.0\%) with advanced defects, consistent with the fact that MME is more likely to occur. Owing to the fact that MME is subject to occurring in patients with advanced glaucoma. Further study of the relationship between the degree of visual field defects and MME is needed.

There were $3(30.0 \%)$ eyes with less than $-20 \mathrm{~dB}$ visual field defect with 24-2 MD eyes. Meanwhile, 8 (80.0\%) eyes were less than $-20 \mathrm{~dB}$ with 10-2 MD. A clinical feature of MME is that the visual field defects in the central 10 degrees are more serious than in the central 24-2 degrees. In all patients, MME was only observed in the parafoveal area. The central visual field defect is relevant to the presence of MME because MME occurs in severe optic neuropathy. In addition, the MD, PSD, and BCVA were significantly worse in eyes with MME in the present study. Therefore, the presence of MME is probably a modifying factor for glaucomatous visual field defects.

We excluded patients with neurological complications from the analysis. It is unlikely that glaucoma is complicated by hypothesized causes of MME such as blood-retinal barrier breakdown or inflammation. ${ }^{11}$ Moreover, MME in all of the patients had already been observed before first glaucoma surgery. The possibility of post-operative inflammation (Irvine-Gass syndrome ${ }^{17}$ ) has been denied. There was a high proportion of glaucoma patients with bilateral MME (42.9\%, three of seven patients) in view of the low incidence of MME (2.1\%, 7 of 341 patients). From these results, we speculate that individual eye factors or systematic diseases are associated with the development of MME. However, we found only one patient with accompanying trochlear nerve palsy, and no patients had any specific risk factor.

Recent investigations have already demonstrated that MME area appears as vacuoles and dark color on enface imaging. ${ }^{6}$ Our findings indicate that MME area can be easily observed with en-face SS-OCT imaging. A previous study had described quantitative MME using OCT B-scan imaging. ${ }^{18}$ In addition, we devised a summary method using Photoshop. There was no significant correlation between MME area and various global HFA indices. Although 24-2 MD values were not correlated with MME area $\left(r_{\mathrm{s}}=0.262, P=0.531\right), 10-2$ MD values were marginally correlated $\left(r_{\mathrm{s}}=-0.571\right.$, $P=0.14)$. Lower 10-2 MD values are associated with larger MME area; therefore, it is necessary to explore more cases of MME and reconsider the relationship between glaucomatous visual field defects and MME area.

This study has several limitations. First, we used SDOCT B-scan imaging to detect the presence of MME in glaucoma patients. Detection of MME was performed using manual, not automatic, methods. It should be noted that there are possibly false-negative patients because the form of vacuole degeneration was mostly involved microstructure in 636 glaucoma patients. Second, the present study was a single hospital-based investigation that was limited to glaucoma patients at our hospital, which treats relatively advanced glaucoma. Thus, the prevalence of MME in glaucoma patients overall may be lower than in our study and other hospital-based studies.

In conclusion, MME was detected in $1.6 \%$ of eyes, based on general inspection, SD-OCT, used in daily clinical examinations. Various data indicated that the presence of MME may contribute to severe visual impairment in the patient with glaucoma. Further research is needed to increase the number of glaucoma patients in order to detect a larger number of eyes with MME and explore the clinical features of patients with MME. 


\section{Summary}

\section{What was known before}

- There have been a few reports about microcystic macular edema in patients with glaucoma. The prevalence rate of MME in patients with glaucoma was still unclear.

\section{What this study adds}

- The current study shows that MME was detected in 1.6\% of eyes, based on general clinical examinations.

- We devised a summary method to evaluate MME area using Photoshop and SS-OCT en-face imaging.

\section{Conflict of interest}

The authors declare no conflict of interest.

\section{Acknowledgements}

The sponsor or funding organization had no role in the design or conduct of this research. We have full control of all primary data and agree to allow EYE to review their data upon request.

\section{References}

1 Thylefors B, Negrel AD. The global impact of glaucoma. Bull World Health Organ 1994; 72: 323-326.

2 Quigley HA, Broman AT. The number of people with glaucoma worldwide in 2010 and 2020. Br J Ophthalmol 2006; 90: 262-267.

3 Airaksinen PJ, Tuulonen A, Werner EB. Clinical evaluation of the optic disc and retinal nerve fiber layer. In: Ritch $R$, Shields MB, Krupin T (eds) The Glaucomas 2nd edn. Mosby: St Louis, MO, USA, 1996, pp 617-657.

4 Stamper RL, Lieberman MF, Drake MV (eds) Becker-Shaffer's Diagnosis and Therapy of Glaucomas 7th edn. Mosby: St Louis, MO, USA, 1999.

5 Wolff B, Basdekidou C, Vasseur V, Mauget-Faysse M, Sahel JA, Vignal C. Retinal inner nuclear layer microcystic changes in optic nerve atrophy: a novel spectral-domain OCT finding. Retina 2013; 33: 2133-2138.

6 Wolff B, Azar G, Vasseur V, Sahel JA, Vignal C, Mauget-Faysse M. Microcystic changes in the retinal internal nuclear layer associated with optic atrophy: a prospective study. J Ophthalmol 2014; 2014: 395189.

7 Hasegawa T, Akagi T, Yoshikawa M, Suda K, Yamada H, Kimura $Y$ et al. Microcystic Inner Nuclear Layer Changes and Retinal Nerve Fiber Layer Defects in Eyes with Glaucoma. PLoS One 2015; 10: e0130175.

8 Gelfand JM, Cree BA, Nolan R, Arnow S, Green AJ. Microcystic inner nuclear layer abnormalities and neuromyelitis optica. JAMA Neurol 2013; 70: 629-633.

9 Saidha S, Sotirchos ES, Ibrahim MA, Crainiceanu CM, Gelfand JM, Sepah YJ et al. Microcystic macular oedema, thickness of the inner nuclear layer of the retina, and disease characteristics in multiple sclerosis: a retrospective study. Lancet Neurol 2012; 11: 963-972.

10 Gelfand JM, Nolan R, Schwartz DM, Graves J, Green AJ. Microcystic macular oedema in multiple sclerosis is associated with disease severity. Brain 2012; 135: 1786-1793.

11 Green AJ, McQuaid S, Hauser SL, Allen IV, Lyness R. Ocular pathology in multiple sclerosis: retinal atrophy and inflammation irrespective of disease duration. Brain 2010; 133: 1591-1601.

12 European Glaucoma Society. Terminology and Guidelines for Glaucoma. 3rd edn. 2008 http: / /www.eugs.org/eng/ EGS_guidelines4.asp (accessed on December 2015).

13 Japan Glaucoma Society. Guidelines for Glaucoma. Japan Glaucoma Society: Tokyo, Japan, 2002.

14 Anderson DR, patella VM. Automated static perimetry 2nd edn. Mosby: St Louis, MO, USA, 1999.

15 Abegg M, Dysli M, Wolf S, Kowal J, Dufour P, Zinkernagel M. Microcystic macular edema: retrograde maculopathy caused by optic neuropathy. Ophthalmology 2014; 121: $142-149$

16 Burggraaff MC, Trieu J, de Vries-Knoppert WA, Balk L, Petzold A. The clinical spectrum of microcystic macular edema. Invest Ophthalmol Vis Sci 2014; 55: 952-961.

17 Irvine SR. A newly defined vitreous syndrome following cataract surgery. Am J Ophthalmol 1953; 36: 599-619.

18 Lang A, Carass A, Swingle EK, Al-Louzi O, Bhargava P, Saidha $\mathrm{S}$ et al. Automatic segmentation of microcystic macular edema in OCT. Biomed Opt Express 2015; 6: 155-169. 